\title{
Lung Development in the Chick Embryo II. Choline and Ethanolamine Kinase Activity in the Developing Lungs of Normal and Hypophysectomized Chick Embryos
}

\author{
SUZANNE K. COMPTON ${ }^{(41)}$ AND GERALD C. GOERINGER \\ Department of Anatomy, Georgetown University, Schools of Medicine and Denistry, Washington, D.C., USA
}

\begin{abstract}
Summary
The developmental pattern of choline kinase and ethanolamine kinase activity (the first enzymes of the choline incorporation and phosphatidylethanolamine methylation pathways for phosphatidylcholine synthesis) was studied in normal chick lungs, between 8 and 21 days of incubation and after hatching, and in the lungs of hypophysectomized chick embryos from 10-20 days of incubation. The $10,000 \times g$ supernatant of lung homogenate was incubated with $\left[{ }^{14} \mathrm{Cl}\right.$-choline or $\left[{ }^{14} \mathrm{C}\right]$-ethanolamine. $\left[{ }^{14} \mathrm{Cl}\right.$-phosphorylcholine or $\left[{ }^{14} \mathrm{C}\right]$-phosphorylethanolamine was separated by paper chromatography and quantitated. Enzyme activity was expressed as nanomoles $\left[{ }^{14} \mathrm{C}\right]$-phosphorylcholine or $\left[{ }^{14} \mathrm{C}\right]$-phosphorylethanolamine produced/mg protein/min. Choline kinase activity decreased between days $8(13.0), 10(10.4)$ and $12(4.0)$. It then increased on days 14 (6.4) and 19 (5.1). In hypophysectomized animals, choline kinase activity dropped from 10.0 on day 10 to 5.9 on day 14 , increased to 8.6 on day 16 , and then decreased on day 19 to 6.7. Choline kinase activity was significantly higher in the lungs of hypophysectomized embryos on days 16, 17, 18, and 20 of incubation. In normal embryos, ethanolamine kinase activity decreased from 1.8 on day 12 to 0.8 by day 14 and again from 1.2 on day 19 to 0.6 by day 20 . In the hypophysectomized embryo, ethanolamine kinase activity decreased from 3.2 on day 10 to 1.3 on day 14 and from 1.6 on day 18 to 0.8 on day 19. Ethanolamine kinase activity was significantly higher in the lungs of hypophysectomized animals on days 10,16, 17, and 18. Choline kinase activity was significantly higher than ethanolamine kinase activity in the normal chick lung on all days of incubation and also after hatching, but was not higher in the adult lung. In the hypophysectomized embryo, choline kinase activity was higher on days 14-20. These data suggest that activity of both enzymes is, at least partially, under endocrine control.
\end{abstract}

\section{Speculation}

Inasmuch as many of the biochemical and morphologic properties of the developing chick lung are similar to those of the mammal, we postulate that at least some of the regulatory mechanisms for lung maturation are also similar. Because the avian embryo is isolated from maternal influences and can be readily hypophysectomized, it promises to be an extremely useful model system in which to study endocrine influences on lung development.

Glucocorticoids $(1,19,24)$, estrogen (8), thyroxine (38), and insulin $(28,29)$ have been implicated in the maturation process of the developing mammalian lung. These hormones appear to enhance fetal lung synthesis of surfactant, especially its major component, dipalmitoyl phosphatidylcholine (33). Conversely, decapitation of the rat fetus at day 16 of gestation delays the appearance of lamellar bodies, decreases the total phospholipid (PL) and phosphatidylcholine (PC) content $(4,5,6)$, and significantly reduces the activity of choline phosphotransferase in the developing lung (14).

The chick lung is very similar to the mammalian lung morphologically and biochemically. Cells that resemble mammalian Type I and Type II pneumocytes have been described in the late embryonic and adult chick lung (31). Turkey lung surfactant, like mammalian, is especially rich in PL and PC (18). Both pathways for de novo PC synthesis, the choline incorporation (I) and phosphatidylethanolamine methylation (II) pathways, are operational in the embryonic and young chick lung (10). Hypophysectomy of the chick embryo at $36 \mathrm{~h}$ of incubation delays the time of appearance of lamellar bodies and decreases the synthesis of PL in the developing lung (27).

If hormones are involved in the regulation of enzymes in the pathways for PC synthesis in the chick embryo, as they appear to be in the mammalian fetus, then hypophysectomy of the embryo at an early age should alter normal patterns of enzyme activity during development. To test this hypothesis, we investigated the activities of choline kinase (E.C.2.7.1.32) and ethanolamine kinase (E.C.2.7.1.8.2), the first enzymes in the two pathways for PC synthesis, in the lungs of normal and hypophysectomized chick embryos, and also in normal newly hatched and adult chickens.

\section{MATERIALS AND METHODS}

Eggs. Embryonated hens' eggs (Truslow Farms, Chestertown, MD), aged $0-18$ days, were incubated at $37^{\circ} \mathrm{C}$ until use. The age of the embryo was determined by: (1) days of incubation, and (2) staging of the embryo according to the criteria of Hamburger and Hamilton (22). Young chicks and adult hens were also obtained from Truslow Farms.

Hypophysectomy of chick embryos. Chick embryos were hypophysectomized at 33-38 h of incubation (Hamburger and Hamilton, stage 10), using the partial decapitation method of Fugo (17). After windowing the egg, the vitelline membrane was slit and the anterior portion of the head was ablated (at the mid-mesencephalic level). Partial decapitation at this stage removes the primordia of the eyes, upper beak, telencephalon, diencephalon, pituitary gland, and the anterior half of the mesencephalon, all of which will not regenerate (2). The window was sealed with transparent tape and paraffin. Operated embryos were returned to the incubator (window-side up) and not subsequently rotated. The primordia of the tongue and lower beak remain and the esophagus remains patent.

Several types of control procedures were used. Surgical controls consisted of embryos in which only portions of the prosencephalon were removed, leaving the primorida of the hypophysis intact. Procedural controls included eggs in which the vitelline membrane was slit but the embryo was left intact. Other eggs were windowed but otherwise left intact. 
Enzyme assays. Choline kinase and ethanolamine kinase activities were assayed according to the methods of Ulane et al. (32). Normal and hypophysectomized embryos between 8 and 21 days, normal newly hatched chicks, and adult chickens were used. Each sample consisted of $300 \mathrm{mg}$ (wet weight) of tissue. For normal lungs, 3-5 samples were assayed at each stage of development studied. Because of the difficulty in obtaining hypophysectomized embryos, 2-4 samples were used for each time period in these experiments. Lungs from all control animals were also assayed.

The lungs were rapidly removed, weighed, and homogenized in 4 volumes of ice cold $0.05 \mathrm{M}$ Tris- $\mathrm{HCl}$ buffer, $\mathrm{pH} 8.5$, and the homogenates centrifuged for $15 \mathrm{~min}$ at $10,000 \mathrm{X} g$ at $4^{\circ} \mathrm{C}$. Replicates of each lung supernatant fluid were assayed for enzyme activity.

For the choline kinase assay, the incubation medium contained $0.01 \mathrm{ml}$ Tris- $\mathrm{HCl}$ (0.4 M, pH 8.5), $0.03 \mathrm{ml} 200 \mathrm{mM} \mathrm{ATP} / 400 \mathrm{mM}$ $\mathrm{MgCl}_{2}, 0.01 \mathrm{ml} 30 \mathrm{mM}$ (methyl- $\left[{ }^{14} \mathrm{C}\right]$-choline chloride (specific activity $=1.62 \mu \mathrm{Ci} / \mu \mathrm{M}$; Amersham Searle) and $0.01 \mathrm{ml}$ lung supernatant fluid. Samples were incubated for $40 \mathrm{~min}$ at room temperature. The reaction was stopped by adding of $0.02 \mathrm{ml}$ glacial acetic acid and placing the samples on ice.

Aliquots $(0.005 \mathrm{ml})$ of each sample were spotted $1 \mathrm{~cm}$ from the bottom end of $9 \times 1.5 \mathrm{~cm}$ strips of Whatman \#3 MM chromatographic paper. Control strips spotted with $0.002 \mathrm{ml}\left[{ }^{14} \mathrm{C}\right]$-choline were prepared.

Chromatograms were run in beakers using a solvent system consisting of $6.5 \mathrm{ml}$ ethyl alcohol, $3.5 \mathrm{ml}$ ammonium hydroxide (30\% ammonia) and $2.0 \mathrm{ml}$ isopropanol. The beakers were sealed with Parafilm. The solvent was allowed to move to approximately $1 \mathrm{~cm}$ from the tops of the strips. After air-drying, the bottom 2.5 $\mathrm{cm}$ of each strip (where the $\left[{ }^{14} \mathrm{C}\right]$-phosphorylcholine remained) was placed in a liquid scintillation vial containing $4 \mathrm{ml}$ of Aquasol (New England Nuclear) (32). The remainder of each strip was placed in a separate vial and all samples were counted in a Searle liquid scintillation counter.

The incubation mixture for the ethanolamine kinase assay consisted of $0.005 \mathrm{ml}$ Tris- $\mathrm{HCl}$ buffer $(0.4 \mathrm{M}, \mathrm{pH} 8.5), 0.015 \mathrm{ml}$ $200 \mathrm{mM}$ ATP $/ 400 \mathrm{mM} \mathrm{MgCl}, 0.005 \mathrm{ml}$ of $60 \mathrm{mM} 2-\left[{ }^{14} \mathrm{C}\right]$ ethan1-ol-2-amine hydrochloride (specific activity $=3.3 \mu \mathrm{Ci} / \mu \mathrm{mol}$; Amersham Searle), and $0.005 \mathrm{ml}$ lung supernatant.

After incubation, chromatograms were prepared as described above and developed in a solvent system consisting of $3.0 \mathrm{ml}$ ethyl alcohol, $5.25 \mathrm{ml}$ ammonium hydroxide (reagent grade $30 \%$ ammonia) and $6.0 \mathrm{ml} n$-butanol. $\left[{ }^{14} \mathrm{C}\right]$-phosphorylethanolamine remained on the bottom $2.5 \mathrm{~cm}$ of the chromatogram. Samples were prepared for liquid scintillation counting as described for the choline kinase assay.

Control chromatograms spotted with $\left[{ }^{14} \mathrm{C}\right]$-choline or $\left[{ }^{14} \mathrm{C}\right]$-ethanolamine showed less than $1 \%$ of the label remained on the bottom $2.5 \mathrm{~cm}$. Efficiency calibration curves showed a $95 \%$ counting efficiency by using the described assay system.

The amount protein/wet weight of tissue was determined for each lung supernatant according to the method of Lowry et al. (25). Choline kinase and ethanolamine kinase activities were expressed as nanomoles $\left[{ }^{14} \mathrm{C}\right]$-phosphorylcholine or $\left[{ }^{14} \mathrm{C}\right]$-phosphorylethanolamine produced/mg protein/min and as $\mathrm{cpm}\left[{ }^{14} \mathrm{C}\right]$ phosphorylcholine or $\left[{ }^{14} \mathrm{C}\right]$-ethanolamine produced/mg protein/ min. The mean and S.E. of the mean were calculated for each time period studied. The difference between means was tested using the two-tailed Student's $t$ test at the $P \leq 0.05$ level.

\section{RESULTS}

Choline kinase activity. In the lungs of normal chick embryos, choline kinase activity was significantly higher in early embryonic life than just before hatching or in the adult lung (Fig. 1). Significant decreases in choline kinase activity occurred between day 8 (13.0) and day $10(10.4)$ and day 12 (4.0). Significant increases in choline kinase activity occurred on days 14 (6.4) and
19 (5.1). From day 20 to adult, choline kinase activity did not vary.

Values for choline kinase activity in the lungs of hypophysectomized embryos did not change significantly over the course of incubation (Fig. 2). Enzyme activity dropped from 10.0 on day 10 to 5.9 by day 14 . By day 16 , activity increased to 8.6 and remained at this level until day 19 of incubation when it dropped to 6.7 .

On days $10,12,14$, and 19, choline kinase activity did not differ in lungs from normal or hypophysectomized embryos; however, activity was significantly higher in the lungs of hypophysectomized animals on days 16, 17, 18, and 20 (Fig. 2).

Choline kinase activity in lungs from both procedural and surgical control embryos was not significantly different from normal lungs of the same age.

Ethanolamine kinase activity. In the normal chick lung, ethanolamine kinase activity was significantly higher early in development than it was just before hatching or in the adult (Fig. 1). Ethanolamine kinase activity decreased from day $12(1.8)$ to day $14(0.8)$ and again from 1.2 on day 19 to 0.6 on day 20 . Other dayto-day changes were not significant. Ethanolamine kinase activity from both procedural and surgical control embryos was not significantly different from normal embryos of the same age.

In the hypophysectomized embryo, ethanolamine kinase activity decreased from day 10 (3.2) to day $14(1.3)$, and from day 18 (1.6) to day 19 (0.8) (Fig. 3). Other day-to-day changes were not significant. Ethanolamine kinase activity was significantly higher in the lungs of hypophysectomized animals than in normals on days $10,16,17$, and 18 .

Choline kinase activity was significantly higher than ethanolamine kinase activity in the normal chick lung on all days of incubation studied and also after hatching, but not in the adult lung (Fig. 1). In hypophysectomized embryos, choline kinase activity was higher than ethanolamine kinase activity on days 14 20 , but not at earlier stages.

\section{DISCUSSION}

During differentiation, the lung is influenced by hormones, enzymes, and other, as yet undefined, factors $(4,30,34)$. One means by which hormones affect development is through regulation of the activity of certain enzymes in the synthetic pathways for PC (34). Therefore, by altering endocrine balance, we should be able to influence enzyme activities. This can be accomplished in the chick embryo by Fugo's technique of hypophysectomy (17). Defects (other than in prosencephalic derivatives) in embryos hypophysectomized by this method are due to the absence of the pituitary (2). Pars distalis grafts or hormone replacement therapy restore functional defects (3).

Hypophysectomy of the rat fetus is done at $\mathbf{1 6}$ days of gestation $(5,6)$. Although pituitary control of endocrine glands does not occur in the rat fetus until 17 days of gestation (23), some glands may be capable of earlier hormonal secretion. For example, in the chick embryo, the adrenal cortex can secrete autonomously as early as 5 days before pituitary regulation occurs (36). If the same is true in the developing mammalian adrenal cortex, then some circulating glucocorticoids may already be present at the time of hypophysectomy. In addition, the stress of a surgical operation in mammals can cause release of maternal hormones such as glucocorticoids that may cross the placenta and affect the developing fetus (20).

The stress response in the chick is characterized by an increase in plasma corticosterone. This response is dependent upon an intact hypothalamic-hypophyseal-adrenal axis, which is only present in the chick after 14 days of incubation (36). Removal of the chick pituitary primordium at $36 \mathrm{~h}$ of incubation eliminates the possibility of any hormonally mediated stress response of the embryo to the surgical procedure; thus, the developing chick lung is a good model system for examining endocrine effects without the confounding interactions of maternal and/or stress responses. 


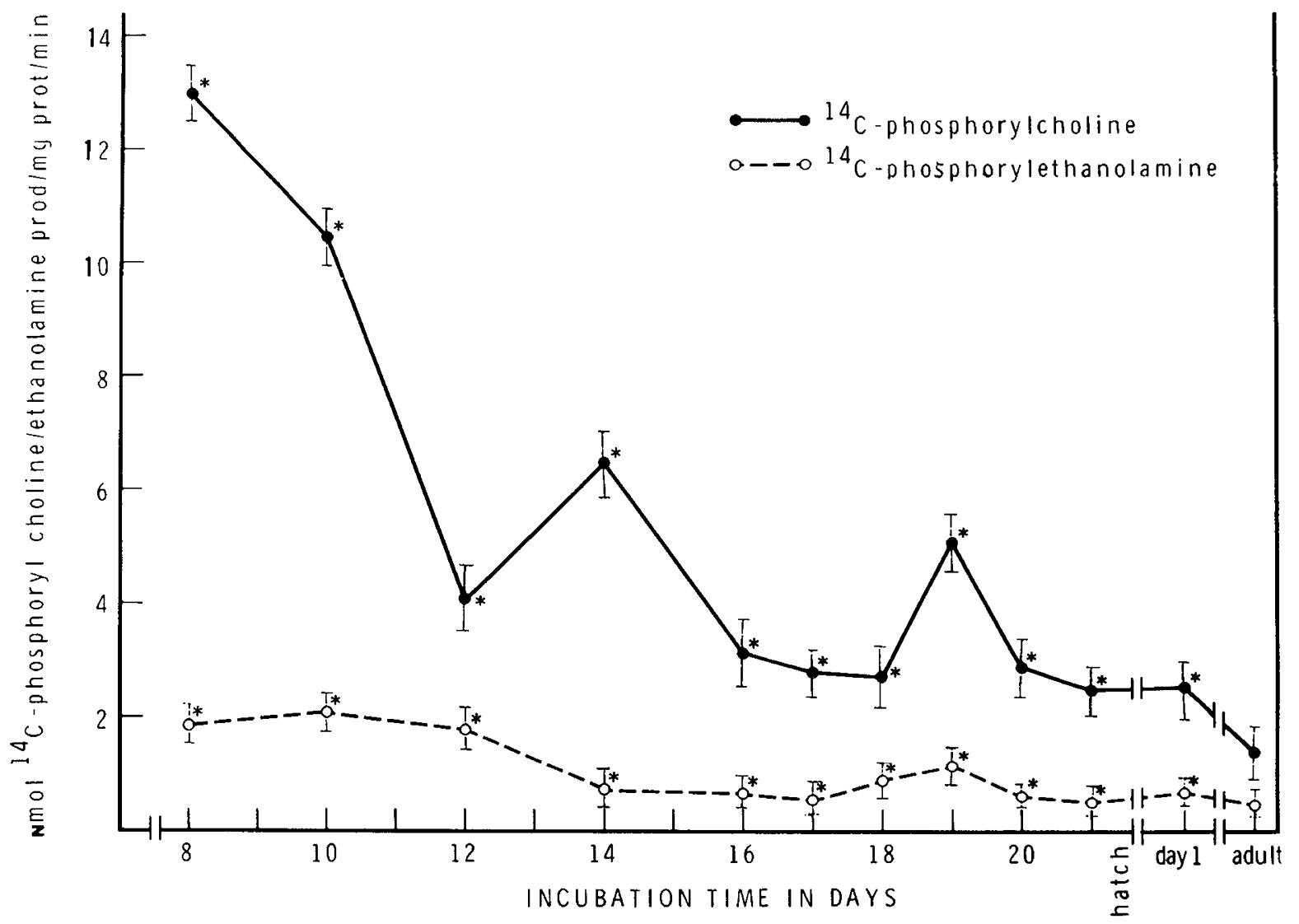

Fig. 1. Choline kinase $(\longrightarrow)$ and ethanolamine kinase $(\mathrm{O}-\mathrm{O}-\mathrm{O})$ activities in the lungs of normal developing chick embryos. Each point represents the mean of 3-5 samples. Each vertical bar represents the S.E. of the mean. ${ }^{*}$ indicates a significant difference $(P \leq 0.05)$ between choline and ethanolamine kinase activities in the lung on that particular day.

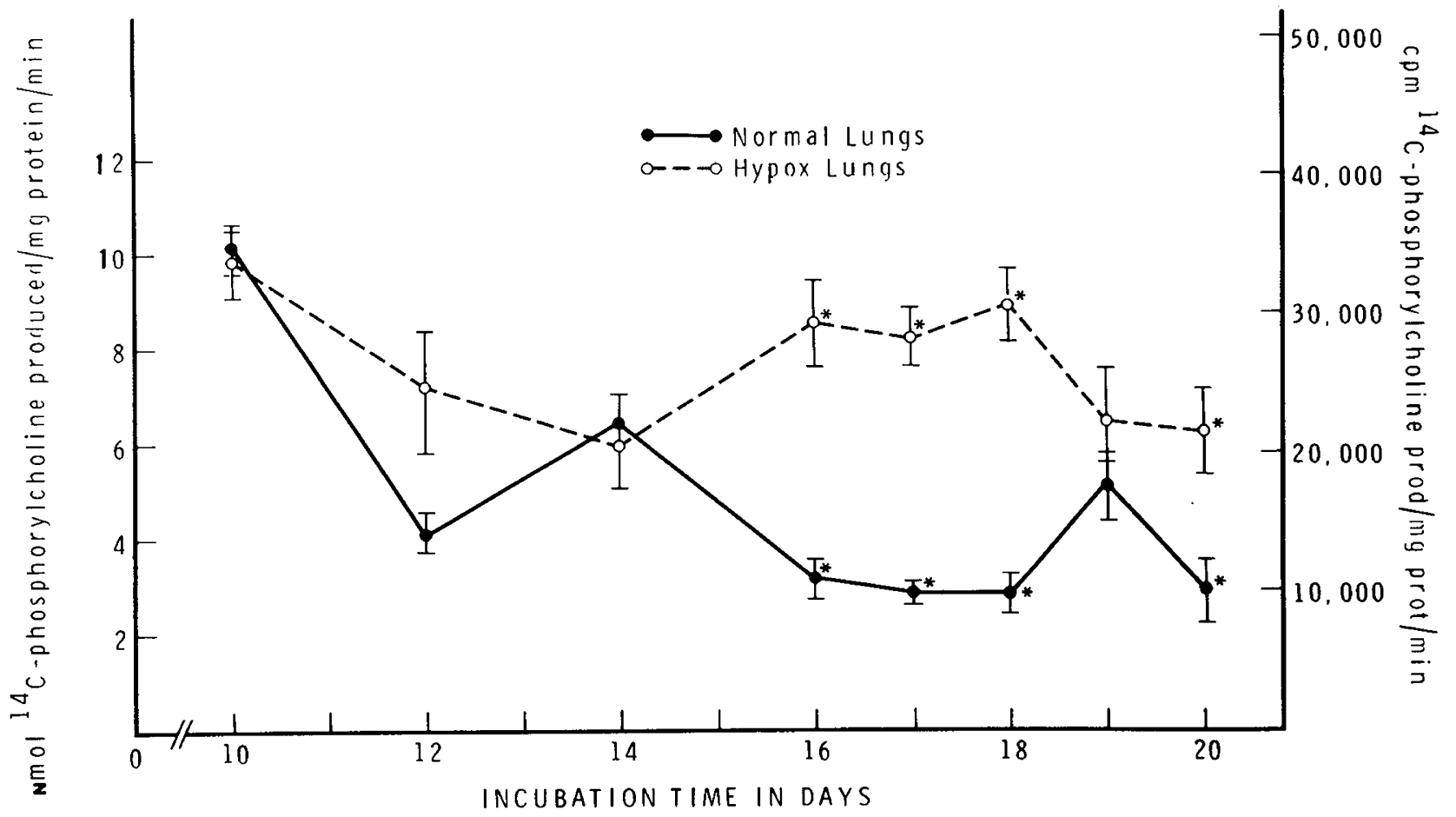

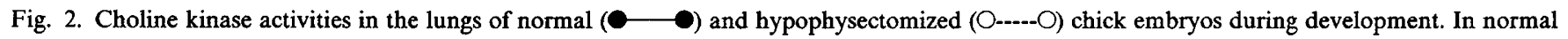
embryos, each point represents the mean of 3-5 samples. In hypophysectomized embryos, each point represents the mean from 2-4 samples. Each vertical bar represents the S.E. of the mean. * indicates a significant difference $(P \leq 0.05)$ in enzyme activity between the lungs of normal and hypophysectomized embryos of the same age. 


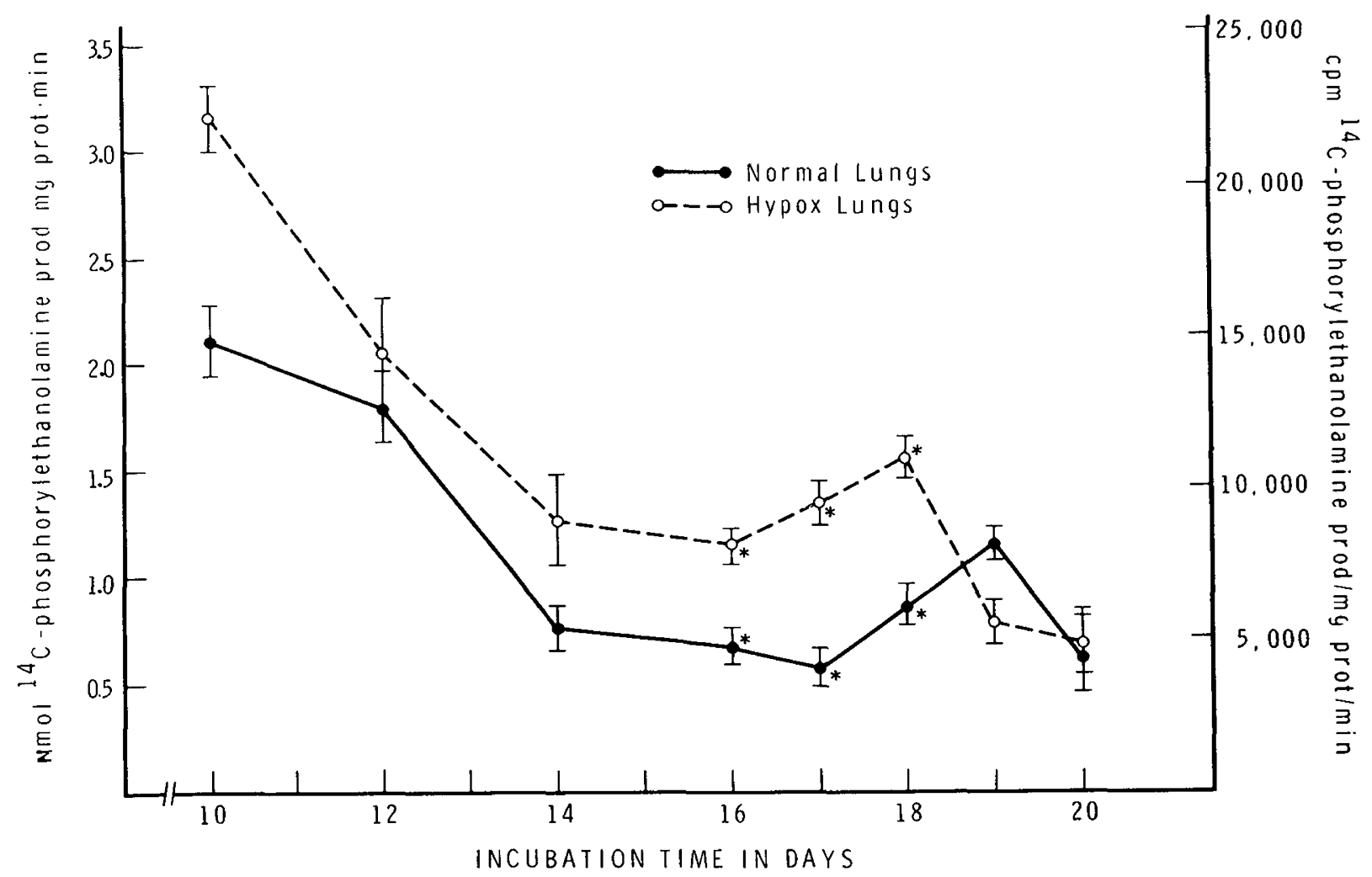

Fig. 3. Ethanolamine kinase activity in the lungs of developing normal $(-0)$ and hypophysectomized $(\mathrm{O}-\mathrm{-}-\mathrm{O})$ chick embryos. In normal embryos, each point represents the mean of 3-5 samples. In hypophysectomized embryos, each point represents the mean of 2-4 samples. Each vertical bar represents the S.E. of the mean. * indicates a significant difference $(P \leq 0.05)$ in enzyme activity between the lungs of normal and hypophysectomized embryos of the same age.

Choline kinase (CK) and ethanolamine kinase (EK) activities were significantly higher in the earlier stages (8-10 days of incubation) of normal developing chick lung. Since PC is a major component of membranes, this high level of activity probably reflects synthesis of membrane PC during the period of active growth of the bronchial tubules. The peak in CK activity on day 14 of incubation occurs at the time when the expanding vascular bed comes in close apposition to the developing air passages, and may also reflect increased membrane synthesis during this stage of development. Lower levels of CK and EK activity, measured on days $16,17,18,20$, and 21 of incubation, may represent the basal level of enzyme activity needed to maintain sufficient synthesis of PC for surfactant $(7,12)$ and cellular membrane requirements.

The peaks in CK and EK activities just before hatching correlate with the increase in synthesis of PC by both pathways at the end of incubation (10). A peak of CK activity in the fetal rat lung before birth was also found by Farrell et al. (16). Chida et al. (9) reported that $\mathrm{CK}$ was much more active in the fetal lung than in the adult; however, both Maniscalco et al. (26) and Weinhold et al. (34) detected no change in CK activity in the fetal rat lung during the last half of gestation. Oldenburg and Van Golde (30) reported a similar lack of change in the fetal mouse lung. There is no clear explanation for the discrepancies in CK activities in these reports (13).

Neither the choline incorporation nor the phosphatidylethanolamine methylation pathway predominated during the last half of incubation in the developing chick lung or in the newly hatched or young chicken lung (10). CK activity was significantly higher than EK activity in the developing lung at all time periods studied. Some of the phosphorylcholine may be used by the embryonic lung to synthesize other compounds, such as sphingomeylin (also a major component of surfactant) and plasmogen (15). Large reservoirs of phosphorylcholine may accumulate in the chick lung during development. Weinhold (35) reported such a pool of phosphorylcholine in the fetal rat lung.
CK activity was lower in the adult chicken lung than in any mammalian lung studied (11); however, because the surface area of the avian lung is much less than that of the mammalian lung, lower $\mathrm{CK}$ activity in the adult chicken lung does not necessarily indicate a slower turnover rate of dipalmitoylphosphatidyl choline in avian surfactant.

Because hypophysectomy has been reported to decrease phospholipid levels in the embryonic chick lung (27), we looked at the effect of hypophysectomy on CK and EK activities. Through 14 days of incubation, the activities of these enzymes did not differ in the lungs of normal and hypophysectomized chick embryos. During this period, hypophyseal control of the endocrine glands had not been completely established (37).

Between days 12 and 14, the pituitary-adrenal axis develops in the chick embryo and the adrenal becomes responsive to ACTH. Differences in activities of both enzymes were detected between the lungs of normal and hypophysectomized chick embryos on day 16. At this time, a significant decrease in circulating levels of corticosterone is seen in the hypophysectomized embryo (36). CK and EK activites remain elevated for most of the remainder of the incubation period in the lungs of hypophysectomized chick embryos.

Decreased phospholipid synthesis in the adult rat lung has been shown to accompany experimental diabetes. The addition of insulin restored PC synthesis to a rate comparable to or greater than that of the normal lung $(28,29)$. Insulin may have a regulatory role in PC synthesis in the lung. In the absence of glucocorticoids and growth hormone (as occurs in the hypophysectomized chick lung), insulin may be responsible for the elevated levels of $\mathrm{CK}$ and $\mathrm{EK}$ activities. Gross et al. (21) have reported an increase in CK activity when 19-day fetal rat lung explants were treated with insulin, athough no increase in PC synthesis was found.

It appears from our data that CK and EK activities are controlled, at least partially, by different mechanisms. In the lungs of hypophysectomized embryos, no significant difference could be found from one day to the next in the activity of CK. Whereas, in 
the normal lung, significant increases and decreases in enzyme activity occur. This suggests that the regulatory mechanisms for this enzyme have been lost in the partial decapitate and that therefore there is endocrine regulation of enzyme levels. EK activity, although elevated over normal levels in the hypophysectomized embryo, does show significant increases and decreases, which suggests both an endocrine and possibly a nonendocrine mode of regulation.

CK and EK activities are high during the early stage of development in the chick lung. Activity of both enzymes peaks just before hatching. The peaks correlate well with increases in PC synthesis before hatching. CK activity is significantly higher than EK activity at all incubation times studied and right after hatching, but not in the adult lung. Hypophysectomy has no effect on CK and EK activities during the early stages of lung development, but both enzyme activities are elevated over normal values during the last half of incubation. Each enzyme appears to be controlled by different mechanisms. Activity of both enzymes is influenced by endocrine factors.

\section{REFERENCES AND NOTES}

1. Avery, M. E.: Acceleration in appearance of pulmonary surfactant in the fetal lamb by administration of corticosteriods. Am. Rev. Respir. Dis., 102: 459 (1970).

2. Betz, T. W.: A method for partial decapitation of chicken embryos: its limitations as a substitute for adenohypophysectomy - an evaluation of "equivalent" methods in amniotes. Acta Endocrinol., (Suppl) 79: 1 (1975).

3. Betz, T. W.: Effects of pars distalis grafts on the development of hypophysectomized chick embryos. Gen. Comp. Endocrinol., 9: 172 (1967)

4. Blackburn, W. R.: Hormonal influences in fetal lung development. In: C. Villee, D. Villee, and J. Zuckerman, Respiratory Distress Syndrome. p. 276, (Academic Press, New York 1974)

5. Blackburn, W. R., Kelly, J., Dickerman, P., Travers, H., Lopata, M., and Rhoades, R.: The role of the pituitary-adrenal-thyroid axes in lung differentiation. II. biochemical studies on developing lung in anencephalic fetal rats. Lab. Invest., 28: 352 (1973)

6. Blackburn, W. R., Travers, H., and Potter, M.: The role of the pituitary-adrenalthyroid axes in lung differentiation. I. studies of the cytology and physical properties of anencephalic fetal rat lung. Lab. Invest., 26: 306 (1972).

7. Brumley, G., Hodson, A., and Avery, M. E.: Lung phospholipids and surface tension correlations in infants with and without hyaline membrane disease and in adults. Pediatrics, 40: 13 (1967)

8. Charles, D. and Chattoraj, S.: Possible role of estradiol-17 and cortisol in the prevention of RDS. In: C. Villee, D. Villee, and J. Zuckerman. Respiratory Distress Syndrome, p. 381 (Academic Press, New York 1974).

9. Chida, N., Hirono, H., Nishimura, Y., and Arakawa, T.: Choline phosphokinase, phosphorylcholine cytidyltransferase and CDP-choline: 1, 2-diglyceride choline-phosphotransferase activity in developing rat lung. Tohoku J. Exp. Med., 110: 273 (1973).

10. Compton, S. and Goeringer, G.: In vitro incorporation of ${ }^{3} \mathrm{H}$-methionine and ${ }^{14} \mathrm{C}$-choline into phosphatidylcholine in the developing chick lung. Pediatr. Res., 15: 866 (1981).

11. Compton, S. and Goeringer, G.: Choline kinase activity in the lungs of different adult mammals. In manuscript, (1982).

12. Epstein, M. F. and Farrell, P. M.: The choline incorporation pathway: primary mechanism for de novo lecithin synthesis in fetal primate lung. Pediatr. Res., 9: 658 (1975).

13. Farrell, P. M. and Hamosh, M.: The biochemistry of fetal lung development. Clin. Perinatol., 5: 197 (1978).

14. Farrell, P. M., Blackburn, W. R., and Adams, A.: Lung phosphatidylcholine synthesis, and choline phosphotransferase activity in anencephalic rat fetuses with corticosteroid deficiency. Pediatr. Res. 11: 770 (1977).

15. Farrell, P. M. and Avery, M. E.: Hyaline membrane disease. In: Lung DiseaseState of Art. p. 1 (American Lung Association, New York, 1976).

16. Farrell, P. M., Lundgren, D. W., and Adams, A. J.: Choline kinase and choline phosphotransferase in developing fetal rat lung. Biochem. Biophys. Res. Commun., 57: 696 (1974).
17. Fugo, N. W.: Effect of hypophysectomy in the chick embryo. J. Exptl. Zoo., 85: 271 (1940).

18. Fujiwara, T., Adams, F. H., Nozaki, M., and Dermer, G. B.: Pulmonary surfactant phospholipids from turkey lung: comparison with rabbit lung. Am. J. Physiol., 218: 218 (1970).

19. Gluck, L. and Kulovich, M.: Fetal lung development, In: Fetal and Postnatal Cellular Growth-Hormones and Nutrition. p. 273 (Wiley and Sons, London, 1975).

20. Greene, R. M. and Kochhar, D. M.: Some aspects of corticosteriod-induced cleft palate: a review. Teratol. 11: 47 (1975).

21. Gross, I. G., Walker Smith, J., Wilson, C. M., Maniscalco, W. M., Ingleson, L. D., Brehier, A., and Rooney, S. A.: The influence of hormones on the biochemical development of fetal rat lung in organ culture. Pediatr. Res., 14: 834 (1981).

22. Hamburger, V. and Hamilton, H.: A series of normal stages in the development of the chick embryo. J. Morph., 88: 49 (1951).

23. Kauffman, S.: Acceleration of canalicular development in lungs of fetal mice exposed transplacentally to dexamethasone. Lab. Invest., 36: 395 (1977).

24. Liggins, G. C. and Howie, R. N.: Prevention of respiratory distress syndrome in premature infants by antepartum glucocorticoid treatment. In: Respiratory Distress Syndrome. pp. 369-380 (Academic Press, New York, 1974)

25. Lowry, O. H., Rosebrough, N. J., Farr, A. L., and Randall, R. J.: Protein measurement with the folin phenol reagent. J. Biol. Chem., 193: 265 (1951).

26. Maniscalco, W. M., Wilson, C., Gross, I., Gobran, L., Rooney, S., and Warshaw, J.: Development of glycogen and phospholipid metabolism in fetal and newborn rat lung. Biochim. Biophys. Acta, 530: 333 (1978).

27. Marin, L., Tordet, C., and Dameron, F.: The endocrine control of embryonic lung maturation in the chicken. I. morphological and biochemical differentiation in lungs after "in ovo" decapitation. Anat. Embryol., 152: 223 (1978).

28. Moxley, M. A. and Longmore, W. J.: Effect of experimental diabetes and insulin on lipid metabolism in the isolated perfused rat lung. Biochim. Acta, 488: 218 (1977).

29. Moxley, M. A. and Longmore, W. J.: Studies on the effects of alloxan and streptozotocin induced diabetes on lipid metabolism in the isolated perfused rat lung. Life Sci., 17: 921 (1975).

30. Oldenburg, V. and Van Golde, L. M. G.: The enzymes of phosphatidylcholine biosynthesis in the fetal mouse lung effects of dexamethasone. Biochim. Biophys. Acta, 489: 454 (1977).

31. Tyler, W. S. and Pangborn, J.: Laminated membrane surface and osmiophilic inclusions in avian lung epithelium. J. Cell Biol., 20: 57 (1964).

32. Ulane, R. E., Stephenson, L., and Farrell, P.: Evidence for the existence of a single enzyme catalyzing the phosphorylation of choline and ethanolamine in primate lung. Biochim. Biophys. Acta, 531: 295 (1978).

33. Weber, G.: Steroid action: phenotypic evidence for reprogramming of gene expression. In: C. Villee, D. Villee, and J. Zuckerman: Respiratory Distress Syndrome, pp 237-270 (Academic Press, New York, 1974).

34. Weinhold, P. A., Sanders, R.. and Stern, W.: Regulation of choline phosphoglyceride synthesis during lung development in the rat. In: C. Villee, D. Villee, and J. Zuckerman: Respiratory Distress Syndrome. p. 29 (Academic Press, New York, 1974).

35. Weinhold, P. A.: Biosynthesis of phosphatidyl choline during prenatal development of the rat lung. J. Lipid Res., 9: 262 (1968).

36. Wise, P. M. and Frye, B. E.: Functional development of the hypothalmohypophyseal-adrenal cortex axis in the chick embryo, Gallus domesticus. J. Exp. Zool., 185: 277 (1973).

37. Woods, J. E., DeVries, G. W., and Thommes, R. C.: Ontogenesis of the pituitaryadrenal axis in the chick embryo. Gen. Comp. Endocrinol., 17: 407 (1971).

38. Wu, B., Kikkawa, Y., Orzales, M. M., Motoyama, E. K., Kaibara, M., Zigas, C. Z., and Cooke, C. D.: The effect of thyroxine on the maturation of fetal rabbit lungs. Biol. Neonate, 22: 161 (1978).

39. The authors wish to thank Dr. Rodney Ulane for his advice during the course of these experiments.

40. The authors are grateful for the laboratory assistance of Nancy Parenteau and Leo Compton.

41. Requests for reprints should be addressed to: Dr. S. K. Compton, Department of Physiology, Georgetown University Schools of Medicine and Dentistry, 3900 Reservoir Road, N.W., Washington, D.C. 20007.

42. This research was supported in part by N.C.I. Contract No. N01-CP-55666, N.I.H. Grants No. RR 5360 and RR 5306 and a Summer Research Fellowship from the Washington Heart Association to S.K.C.

43. Received for publication August 13, 1980.

44. Accepted for publication January 8, 1982. 